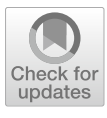

Cite as

Nano-Micro Lett.

(2020) 12:114

Received: 22 March 2020

Accepted: 1 May 2020

Published online: 22 May 2020

(C) The Author(s) 2020

\section{Self-Assembled Al Nanostructure/ZnO Quantum Dot Heterostructures for High Responsivity and Fast UV Photodetector}

\author{
Sisi Liu ${ }^{1}$, Ming-Yu Li ${ }^{2}{ }^{凶}$, Jianbing Zhang ${ }^{1}$, Dong $\mathrm{Su}^{1}$, Zhen Huang ${ }^{3}$, Sundar Kunwar ${ }^{4}$, \\ Jihoon Lee ${ }^{4,5}$ \\ $\triangle$ Ming-Yu Li, mingyuli.oliver@gmail.com \\ 1 School of Optical and Electronic Information, Huazhong University of Science and Technology, \\ Wuhan 430074, People's Republic of China \\ 2 School of Science, Wuhan University of Technology, Wuhan 430070, People's Republic of China \\ 3 Wuhan National Laboratory for Optoelectronics (WNLO) and School of Engineering Sciences, Huazhong \\ University of Science and Technology, Wuhan 430074, People's Republic of China \\ 4 College of Electonics and Information, Kwangwoon University, Nowon-gu, Seoul 01897, Republic of Korea \\ 5 Institute of Nanoscale Science and Engineering, University of Arkansas, Fayetteville, AR 72701, USA
}

\title{
HIGHLIGHTS
}

- High performance Al nanostructures/ZnO quantum dots heterostructure photodetectors with a controllable geometry of the Al nanostructures are demonstrated.

- Light utilization of the photoactive layers is significantly boosted with the Al nanostructures.

- The light confinement effect is inherently determined by the geometries of the Al nanostructures.

\begin{abstract}
Light confinement induced by spontaneous near-surface resonance is inherently determined by the location and geometry of metallic nanostructures (NSs), offering a facile and effective approach to break through the limitation of the light-mater interaction within the photoactive layers. Here, we demonstrate high-performance $\mathrm{Al} \mathrm{NS} / \mathrm{ZnO}$ quantum dots $(\mathrm{Al} / \mathrm{ZnO})$ heterostructure $\mathrm{UV}$ photodetectors with controllable morphologies of the self-assembled Al NSs. The $\mathrm{Al} / \mathrm{ZnO}$ heterostructures exhibit a superior light utilization than the $\mathrm{ZnO}$ / $\mathrm{Al}$ heterostructures, and a strong morphological dependence of the Al NSs on

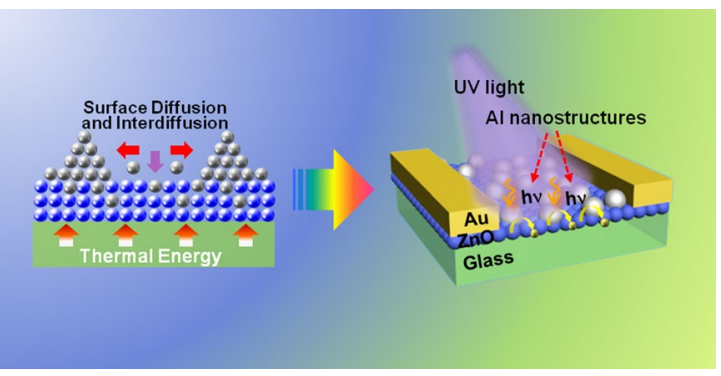
the optical properties of the heterostructures. The inter-diffusion of $\mathrm{Al}$ atoms into $\mathrm{ZnO}$ matrixes is of a great benefit for the carrier transportation. Consequently, the optimal photocurrent of the $\mathrm{Al} / \mathrm{ZnO}$ heterostructure photodetectors is significantly increased by 275 times to $~ 1.065 \mathrm{~mA}$ compared to that of the pristine $\mathrm{ZnO}$ device, and an outstanding photoresponsivity of $11.98 \mathrm{~A} \mathrm{~W}^{-1}$ is correspondingly achieved under $6.9 \mathrm{~mW} \mathrm{~cm}^{-2} \mathrm{UV}$ light illumination at $10 \mathrm{~V}$ bias. In addition, a relatively fast response is similarly witnessed with the $\mathrm{Al} / \mathrm{ZnO}$ devices, paving a path to fabricate the high-performance UV photodetectors for applications.
\end{abstract}

KEYWORDS Al/ZnO heterostructure photodetectors; Plasmonic enhancement; ZnO quantum dots; Self-assembled Al nanostructures 


\section{Introduction}

Owing to their excellent characteristics of intrinsic anti-interference from the visible region [1], filter free [2], and high radiation hardness [3], UV photodetectors (PDs) have been widely witnessed in civilian and military fields, including intersatellite communications [4], optical imaging [5], flame sensing [6], environmental monitoring [7, 8], and missile detection [9]. Among various $\mathrm{UV}$ photo-electronic materials (i.e., $\mathrm{GaN}, \mathrm{SiC}, \mathrm{SnO}_{2}$, and $\left.\mathrm{TiO}_{2}[10,11]\right), \mathrm{ZnO}$ has great potential to fabricate highperformance UV photodetectors because of its wide direct bandgap of $\sim 3.37 \mathrm{eV}$, high saturated carrier drift rate, large exciton energy $(60 \mathrm{meV})[12,13]$. Whereas, the conventional $\mathrm{ZnO}$ single crystal and thin-film photodetectors commonly suffer from a large dislocation density, excessive grain boundaries, and high-cost fabrication, resulting in radical deterioration of photoresponse for the devices [14]. Meanwhile, the solution-processed $\mathrm{ZnO}$ nanostructures (NSs) (i.e., quantum dots (QDs), nanowires, and nanodisks) emerged with high adjustability, physical flexibility, and low cost, offering a promising approach to achieve the high-performance detectors in practical fabrication [10]. Additionally, the high specific surface area of the $\mathrm{ZnO}$ NSs allows additional oxygen absorption, and a relatively lower dark current and high on/off ratio can correspondingly be expected with extended low-conductive depletion regions $[10,15]$. However, the dimension of the ZnO NSs inevitably limits the light utilization and carrier transportation, which have become a huge challenge for the fabrication of ultra-sensitive photodetectors working with a fast response [15].

Localized surface plasmon resonance (LSPR), spontaneously collective charge oscillation on the surface of metallic NSs [16], provides a facile way to boost the light absorption for photoactive layers via concentrating the incident lights at the metal NSs-semiconductor interface [17]. The resonance wavelength can be inherently varied depending on metals, and the traditional noble metals ( $\mathrm{Au}$ and $\mathrm{Ag}$ ) exhibit a radical response in the visible region [18]. Thus, cost-effective metallic NSs with a desired response wavelength are required to effectively intensify the light utilization of $\mathrm{ZnO}$ layers. According to the Mie theory, the dielectric function of Al possess a negative real part $\left(\varepsilon^{\prime}\right)$ and relatively low imaginary part $\left(\varepsilon^{\prime \prime}\right)$ throughout the whole region [19], suggesting an excellent potential to guarantee a superior plasmon resonance within the response wavelength range of $\mathrm{ZnO}$ photodetectors. In addition, $\mathrm{Al}$ is regarded as earth-abundant and low-cost, and $\mathrm{Al}$ atoms can easily diffuse into $\mathrm{ZnO}$ matrixes under high temperature annealing to form a layer with a large carrier mobility [20]. In the light of the advantages, Al NSs potentially provides an optimized solution for the fabrication of high-performance $\mathrm{ZnO} \mathrm{UV}$ photodetectors. $\mathrm{Up}$ to date, researchers have focused on the fabrication of Al-doped $\mathrm{ZnO}$ (AZO) transparent conductive oxide thin films, and the application of $\mathrm{Al} \mathrm{NSs} \mathrm{in} \mathrm{ZnO}$ photodetectors has been rarely reported.

Herein, we report a high-performance ZnO QD UV photodetector with the self-assembled Al NSs fabricated via the cost-effective and facile solid-state dewetting method. The solar energy utilization of the photoactive layers strongly depends on the configuration of the heterostructures and morphologies of the resulting Al NSs due to the variation of the plasmonic coupling. As a result, the UV photodetector with $\mathrm{Al} / \mathrm{ZnO}$ heterostructures fabricated at $500{ }^{\circ} \mathrm{C}$ exhibit an excellent photocurrent of $1.065 \mathrm{~mA}$ and photoresponsivity of $11.98 \mathrm{~A} \mathrm{~W}^{-1}$ under $6.9 \mathrm{~mW} \mathrm{~cm}^{-2}$ light illumination at a bias of $10 \mathrm{~V}$. In addition, the fast response speed is witnessed with each device, and the $\tau_{\text {rise }}$ and $\tau_{\text {decay }}$ of the $\mathrm{Al} / \mathrm{ZnO}$ heterostructure photodetector even decrease to $\sim 0.79 \mathrm{~s}$ and $\sim 0.24 \mathrm{~s}$, suggesting a promising solution for the high-performance photodetector fabrication in the practical applications.

\section{Experimental}

\subsection{ZnO QDs Synthesis}

ZnO QDs were synthesized by the solvothermal method as reported in our previous work [1, 21]. In brief, $2.49 \mathrm{~g}$ zinc acetate $\left(\mathrm{Zn}\left(\mathrm{CH}_{3} \mathrm{COO}\right)_{2}, 99.99 \%\right.$, Aladdin, CAS: $5970-$ 45-6) was dissolved into $126 \mathrm{~mL}$ methanol by stirring at $60{ }^{\circ} \mathrm{C}$. Subsequently, $23 \mathrm{ml}$ potassium hydroxide $(\mathrm{KOH})$ methanol solution (CAS: 67-56-1) by dissolving $1.29 \mathrm{~g}$ KOH (85\%, Aladdin, CAS: 1310-58-3) slowly dropped into the zinc acetate methanol solution. The mixtures were heating at $60{ }^{\circ} \mathrm{C}$ for $2.25 \mathrm{~h}$ with vigorously stirring, and then were naturally cooled to room temperature. After 
twice washing with methanol by precipitation method, the product was finally dispersed in a mixed solvent of chloroform and methanol ( $6 \mathrm{~mL}, 2: 1$ by volume). As revealed in Fig. S1a, the resulting $\mathrm{ZnO}$ QDs have average size of $7 \mathrm{~nm}$, and the absorption bands well developed below $360 \mathrm{~nm}$ in the absorbance spectra in Fig. S1b.

\subsection{Heterostructure Photodetector Fabrication}

The photodetectors were fabricated on the glass substrates with two configurations to study the influence of stacking-order between $\mathrm{ZnO}$ QD and Al NSs on the light trapping as shown in Fig. 1a. Prior to the fabrication, the glass substrates were successively cleaned through $15 \mathrm{~min}$ ultrasonification in deionized water and acetone, and then were degassed at $500{ }^{\circ} \mathrm{C}$ for 30 min under a vacuum below $1 \times 10^{-4}$ Torr to remove the residual chemicals on the surface. After cleaning, $\mathrm{Al}$ thin films with a thickness of $6 \mathrm{~nm}$ was deposited on the glass via thermal evaporation at a rate of $0.1 \mathrm{~nm} \mathrm{~s}^{-1}$ under $1 \times 10^{-4} \mathrm{~Pa}$. The self-assembled $\mathrm{Al}$ NSs were fabricated via the solid-state dewetting method [22] at $500{ }^{\circ} \mathrm{C}$ in a rapid thermal annealing furnace (OTF1200-4-RTP, Hefeikejing Materials Technology Co., Ltd.,

(a)
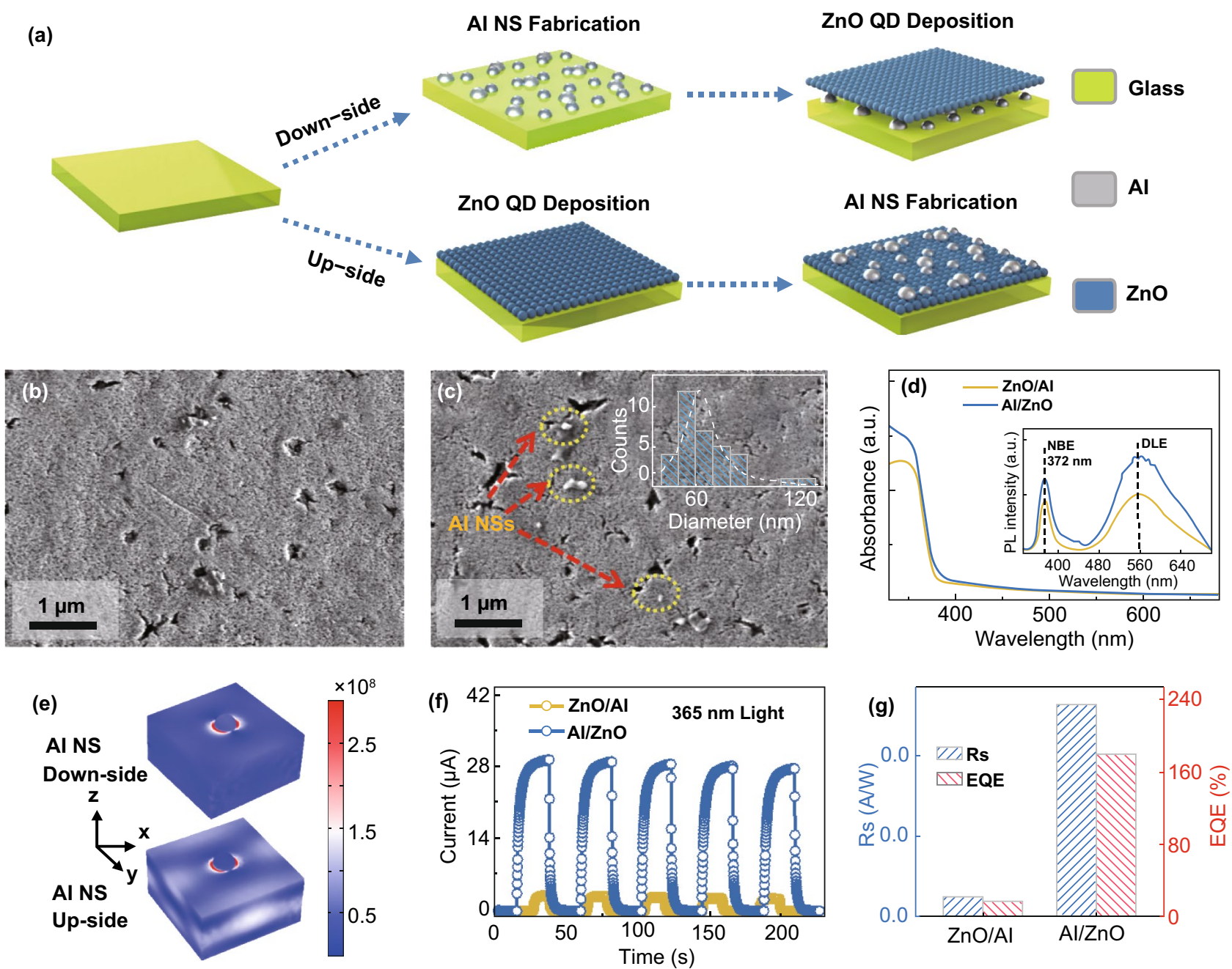

Fig. 1 a Schematics of the fabrication process for heterostructure photodetectors with the assembled $\mathrm{Al}$ nanostructures under (ZnO/Al sample) and on ( $\mathrm{Al} / \mathrm{ZnO}$ sample) the $\mathrm{ZnO}$ photoactive layer. SEM images of the $\mathbf{b} \mathrm{ZnO} / \mathrm{Al}$ and $\mathbf{c} \mathrm{Al} / \mathrm{ZnO}$ devices. (Insets) The size distribution histograms of the Al NSs. d Absorbance spectra and room-temperature PL emission spectra (insets) of the Al/ZnO and $\mathrm{ZnO} / \mathrm{Al}$ devices. e Electromagnetic (EM) filed distribution of the samples $\mathrm{Al} / \mathrm{ZnO}$ and $\mathrm{ZnO} / \mathrm{Al}$ via the COMSOL simulation. $\mathbf{f}$ Temporal photoresponse of the $\mathrm{Al} / \mathrm{ZnO}$ and $\mathrm{ZnO} / \mathrm{Al}$ devices under $365 \mathrm{~nm}$ light illumination $\left(6.9 \mathrm{~mW} \mathrm{~cm}^{-2}\right)$ at a bias of $10 \mathrm{~V}$. $\mathrm{g}$ Photoresponsivity $\left(R_{s}\right)$ and external quantum efficiency (EQE) of each device 
China) under $1 \times 10^{-5}$ Torr (a molecular pump was equiped to extend the pressure range). As shown in Fig. S1c, the pronounced absorption bands of the resulting Al NSs appeared below $400 \mathrm{~nm}$, which exactly matched the response wavelength range of $\mathrm{ZnO}$ QDs. The $\mathrm{ZnO}$ QD photoactive layers were subsequently deposited on the Al nanostructures by layer-by-layer spin-coating at a speed of $2000 \mathrm{rpm}$ for $30 \mathrm{~s}$ (the $\mathrm{ZnO} / \mathrm{Al}$ heterostructure photodetector). To evaluate the temperature effects, the $\mathrm{Al} \mathrm{NSs}$ was fabricated at $300{ }^{\circ} \mathrm{C}$ (Al/ZnO-300), $400{ }^{\circ} \mathrm{C}(\mathrm{Al} / \mathrm{ZnO}-400), 500{ }^{\circ} \mathrm{C}(\mathrm{Al} / \mathrm{ZnO}-500)$ with an identical deposition thickness of $6 \mathrm{~nm}$ on the spincoated $\mathrm{ZnO}$ QD thin films. To investigate the deposition thickness effects, the Al NSs were fabricated on $\mathrm{ZnO}$ QD thin films at a fixed annealing temperature of $500{ }^{\circ} \mathrm{C}$ with various deposition thicknesses: $6 \mathrm{~nm}(\mathrm{Al} / \mathrm{ZnO}-6 \mathrm{~nm}), 8 \mathrm{~nm}$ $(\mathrm{Al} / \mathrm{ZnO}-8 \mathrm{~nm})$, and $10 \mathrm{~nm}(\mathrm{Al} / \mathrm{ZnO}-10 \mathrm{~nm})$. As reference, the pristine $\mathrm{ZnO}$ devices were annealed at 300 to $500{ }^{\circ} \mathrm{C}$, and the device structure is shown in Fig. S1d. Finally, a pair of Au electrodes with a length of $4 \mathrm{~mm}$ and a gap distance of $200 \mu \mathrm{m}$ was deposited on each sample to fabricate photodetector as shown in Fig. S2a. The Commercial COMSOL solution software was employed for the simulation of the EM field distribution of the heterostructures, and the parameters in simulations were the statistic values required from the SEM images.

\subsection{Characterization}

The absorption spectra of the Al NSs and $\mathrm{Al} / \mathrm{ZnO}$ heterostructures were recorded with a UV-vis spectrophotometer (UV 3600 Plus, Japan). The room-temperature photoluminescence (PL) spectra were obtained via a Raman microscope with an excitation laser of $325 \mathrm{~nm}$ (LabRAM HR800, Horiba JobinYvon Corp., France). The transmission electron microscope (TEM, TF20, FEI Tecnai Corp., USA) was utilized for morphological characterization of the $\mathrm{ZnO}$ QD. The scanning electron microscope (SEM, GeminiSEM 300, Carl Zeiss Microscopy GmbH, Corp., Germany) was employed for the morphological characterization of the Al/ $\mathrm{ZnO}$ heterostructures. The element analysis was carried out with the energy dispersive spectroscopy (EDS, GeminiSEM 300, Carl Zeiss Microscopy GmbH, Corp., Germany) and $\mathrm{X}$-ray photoelectron spectroscopy using $\mathrm{Al} \mathrm{K} \alpha$ excitation (XPS, Thermo Fisher, EscaLab 250Xi). The performance of the photodetectors was measured by a semiconductor device analyzer (Agilent technologies B1500A, America) inside an optically and electrically sealed box. The lighting source was light-emitting diodes controlled by a functional generator (Agilent 33210A).

\section{Results and Discussion}

\subsection{Configuration Effect on Device Performance}

Figure 1 shows the configuration effect on the performance of $\mathrm{ZnO}$ QD photodetectors with the self-assembled Al NSs fabricated on $(\mathrm{Al} / \mathrm{ZnO}) /$ under $(\mathrm{ZnO} / \mathrm{Al})$ photoactive layers, and the fabrication process is depicted in Fig. 1a. As shown in Fig. 1b, c, continuous geometry of the $\mathrm{ZnO}$ QD thin films was witnessed on each device, and sparse Al NSs spontaneously aggregated on the $\mathrm{ZnO}$ QD thin films with an average diameter $\left(D_{\text {ave }}\right)$ of $\sim 64.8 \mathrm{~nm}$ for the $\mathrm{Al} / \mathrm{ZnO}$ sample, suggesting a favorable surface diffusion of $\mathrm{Al}$ atoms after annealing. To understand the carrier generation process for each configuration, the absorption and room-temperature PL after $325 \mathrm{~nm}$ laser excitation were investigated as shown in Fig. 1d. The absorption edge peak below $\sim 375 \mathrm{~nm}$ was similarly observed for each sample, and absorption was obviously enhanced for the $\mathrm{Al} /$ $\mathrm{ZnO}$ sample in the light of the concentrated incident lights with intensified near-surface EM fields. Correspondingly, the near-band-edge (NBE) excitonic emission peak at $\sim 372 \mathrm{~nm}$ and defect-related emission (DLE) peak at $\sim 560 \mathrm{~nm}$ were drastically increased for $\mathrm{Al} / \mathrm{ZnO}$ sample than that of the $\mathrm{ZnO} /$ Al sample, which was because of the intensified recombination with extra electron-hole pairs excited by the concentrated incident lights [23]. As clearly shown in Fig. 1e, the EM in $\mathrm{ZnO}$ layers was drastically intensified for the $\mathrm{Al} / \mathrm{ZnO}$ sample, indicating the light confinement effect for the absorption. In addition, the comparison of the performance of the $\mathrm{Al} / \mathrm{ZnO}$ and $\mathrm{ZnO} / \mathrm{Al}$ devices are shown in Figs. $1 \mathrm{f}-\mathrm{g}$ and $\mathrm{S} 2 \mathrm{~b}$, c. As shown in Fig. S2b, a slightly higher current $\left(I_{\mathrm{d}}\right)$ of the $\mathrm{A} / \mathrm{ZnO}$ detector was similarly witnessed at each bias voltage in the dark, which was probably attributed to the increased conductivity of $\mathrm{ZnO}$ layers induced by the diffusion for $\mathrm{Al}$ atoms into $\mathrm{ZnO}$ lattice during annealing [24]. Meanwhile, the photocurrents $\left(I_{\mathrm{ph}}\right)$ of the $\mathrm{Al} / \mathrm{ZnO}$ detector were obviously higher than that of the $\mathrm{ZnO} / \mathrm{Al}$ one with a variation of voltage bias due to the additional excited carriers by the concentrated lights as revealed in Fig. S2c. As a consequence, the $I_{\mathrm{ph}}$ of the Al/ $\mathrm{ZnO}$ photodetector remarkably enhanced 10.3 times than that 
of the $\mathrm{ZnO} / \mathrm{Al}$ one at a bias of $10 \mathrm{~V}$ as shown in Fig. 1f, and the temporal response in multiple on/off cycles verified the superior stability and repeatability of the resulting devices. The responsivity $\left(R_{s}\right)$ of detectors suggests of the electrical signal generation converting from incident lights, which can be expressed as Eq. 1 [25]:

$R_{s}=\frac{\left(I_{\mathrm{ph}}-I_{\mathrm{d}}\right)}{P_{0} A}$

where $P_{0}$ is the light power $\left(6.9 \mathrm{~mW} \mathrm{~cm}^{-2}\right)$ and $A$ is the active area of the devices. As shown in Fig. $1 \mathrm{~g}$, the $\mathrm{Al} / \mathrm{ZnO}$ device exhibited the $R_{S}$ of $\sim 0.529 \mathrm{~A} \mathrm{~W}^{-1}$, which increased by $926 \%$ than the $R_{S}$ of $\mathrm{ZnO} / \mathrm{Al}$ device. The external quantum efficiency (EQE), the ability of electrons excitation by incident photons, can be given with Eq. 2 [26]:

$\mathrm{EQE}=R_{s} \times \frac{1240}{\lambda} \times 100$

where $\lambda$ is the incident wavelength of $365 \mathrm{~nm}$. As shown in Fig. 1g, the EQE increased by 10.3 times to $~ 179.6 \%$ for the $\mathrm{Al} / \mathrm{ZnO}$ device in comparison with the $\mathrm{ZnO} / \mathrm{Al}$ device.

\subsection{Annealing Temperature Effect on Device Performance}

To further understand the evolution behavior, the self-assembled $\mathrm{Al} \mathrm{NSs}$ were fabricated on $\mathrm{ZnO}$ thin films with a variation of annealing temperatures between 300 and $500{ }^{\circ} \mathrm{C}$ on $\mathrm{ZnO}$ QD thin films as shown in Fig. 2. As shown in Figs. 2a-c, the $\mathrm{Al}$ atoms spontaneously aggregated into the NSs at $300{ }^{\circ} \mathrm{C}$ when compared with the relatively smooth morphology of the pristine $\mathrm{ZnO}$ thin films, and the size expansion of the sparse Al NSs was observed as a function of annealing temperatures. Correspondingly, the $D_{\text {ave }}$ of the resulting Al NSs gradually increased from $\sim 48.3$ to $\sim 64.8 \mathrm{~nm}$ from 300 to $500^{\circ} \mathrm{C}$ as plotted in Fig. 2d. Generally, the $\mathrm{Al}$ atoms were sensitive to thermal energy, and the competition between surface aggregation and inter-diffusion of $\mathrm{Al}$ atoms determined the resulting morphology of the Al NSs. As depicted in Fig. 2e, Al atoms were activated to randomly nucleate with thermal energy supply, and the diffusion length of $\mathrm{Al}$ atoms $\left(L_{\mathrm{Al}}\right)$ on the $\mathrm{ZnO}$ thin films can be given with Eq. 3 [27, 28]

$L_{\mathrm{Al}} \propto \sqrt{\exp \left(-E_{\mathrm{Al}} / k T\right) \times t}$

where $E_{\mathrm{Al}}$ is the activation energy, $k$ is the Boltzmann constant, $T$ is the annealing temperature, and $t$ is the residence time of $\mathrm{Al}$ atoms on the $\mathrm{ZnO}$ thin films. Thus, the $L_{\mathrm{Al}}$ can be inherently determined by the $T$, and the size expansion of the $\mathrm{Al}$ NSs was correspondingly observed due to the favorable surface diffusion of atoms with a broadened $L_{\mathrm{Al}}$. Meanwhile, the inter-diffusion of $\mathrm{Al}$ atoms into $\mathrm{ZnO}$ matrixes was concurrently accelerated along with the increasing $T$, resulting in an evident density decrease of Al NSs during the evolution. Additionally, the element distribution of the $\mathrm{Al} / \mathrm{ZnO}$ heterostructures fabricated at $500{ }^{\circ} \mathrm{C}$ was analyzed by EDS as shown in Fig. 2f, g. As observed in Fig. 2f, the Zn (green), $\mathrm{O}$ (yellow), and $\mathrm{Al}$ (red) uniformly distributed throughout the whole structures, indicating the inter-diffusion of $\mathrm{Al}$ atoms. The existence of $\mathrm{Al}$ can be further evidenced with the $\mathrm{K} \alpha$ peak at $1.49 \mathrm{eV}$ as shown with the EDS spectra in Fig. 2g [29].

The performance of the $\mathrm{Al} / \mathrm{ZnO}$ heterostructure UV photodetectors with the self-assembled Al NSs fabricated at diverse annealing temperatures was systematically investigated as shown in Fig. 3, and the corresponding values are summarized in Table 1. As shown in Fig. 3a, the Al/ $\mathrm{ZnO}$ heterostructure $\mathrm{UV}$ photodetectors exhibited relatively higher $I_{\mathrm{d}}$ than that of pristine one at each bias due to the introduction of $\mathrm{Al}$ atoms [24], and the $I_{\mathrm{d}}$ gradually increased as a function of the annealing temperature arising from the accelerated inter-diffusion of $\mathrm{Al}$ atoms. Meanwhile, the temperature dependence on the $I_{\mathrm{ph}}$ was observed at each bias, and the $I_{\mathrm{ph}}$ of the $\mathrm{Al} / \mathrm{ZnO}$ detectors was obviously improved in comparison with the pristine $\mathrm{ZnO}$ device under 365 light illumination as revealed in Fig. 3b. As a result, the $I_{\mathrm{ph}}$ of the detector $\mathrm{Al} / \mathrm{ZnO}-500$ noticeably increased by $1010 \%$ to $\sim 29.2 \mu \mathrm{A}$ than the pristine $\mathrm{ZnO}$ device of $\sim 2.63 \mu \mathrm{A}$ at $10 \mathrm{~V}$ bias under the UV light illumination as summarized in Table 1. In addition, the $I_{\mathrm{ph}}$ of $\mathrm{ZnO}$ photodetectors significantly lower than that of $\mathrm{Al} / \mathrm{ZnO}$ heterostructure device at each annealing temperature, as shown in Fig. S2d. Moreover, each $\mathrm{Al} / \mathrm{ZnO}$ heterostructure photodetector sensitively responded to the UV light with a fast speed, which can be verified with the rise time $\left(\tau_{\text {rise }}\right.$, the period of the current increased to $\left.I_{\mathrm{ph}} / \mathrm{e}\right)$ and decay time $\left(\tau_{\text {decay }}\right.$, period of the current decreased to $\left.I_{\mathrm{ph}} \times(1-1 / \mathrm{e})\right)$ as shown in Figs. $3 \mathrm{c}, \mathrm{d}$ and S3. Compared with the pristine $\mathrm{ZnO}$ device, the $\tau_{\text {rise }}$ and $\tau_{\text {decay }}$ of the device Al/ZnO-300 decreased to $\sim 0.79 \mathrm{~s}$ and $\sim 0.24 \mathrm{~s}$. The response speed of the $\mathrm{Al} / \mathrm{ZnO}$ heterostructure photodetector was apparently superior to previously reported ZnO-based UV photodetectors [4, 30-32], and was even faster than our previously reported $\mathrm{Cu} / \mathrm{ZnO}$ hybrid architecture photodetectors [1]. The light intensity 

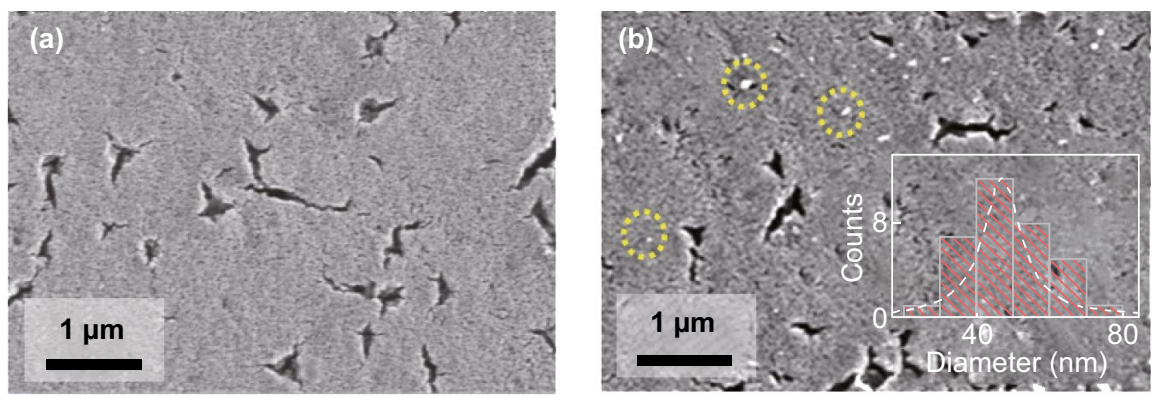

\section{(e) Material Deposition}
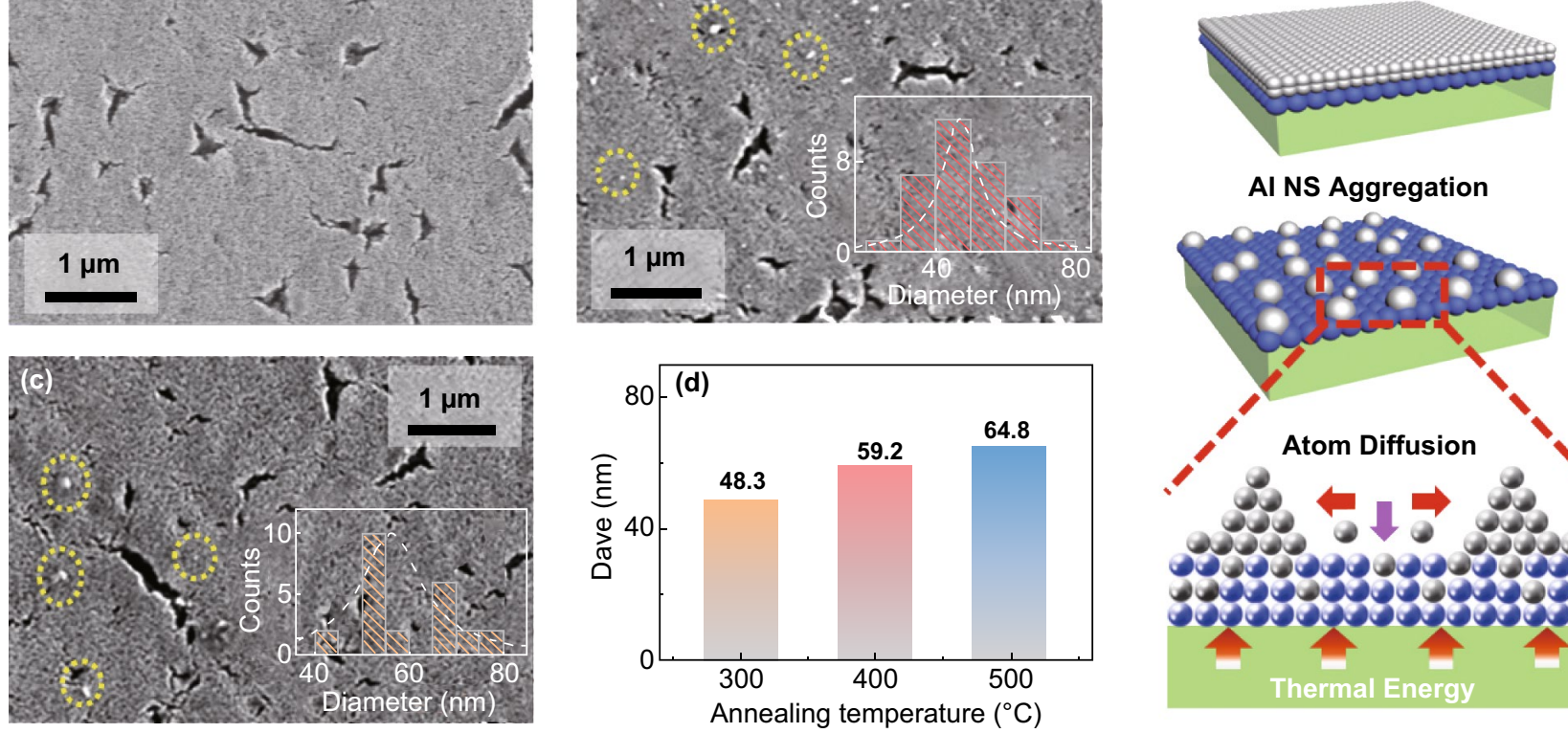

Al NS Aggregation
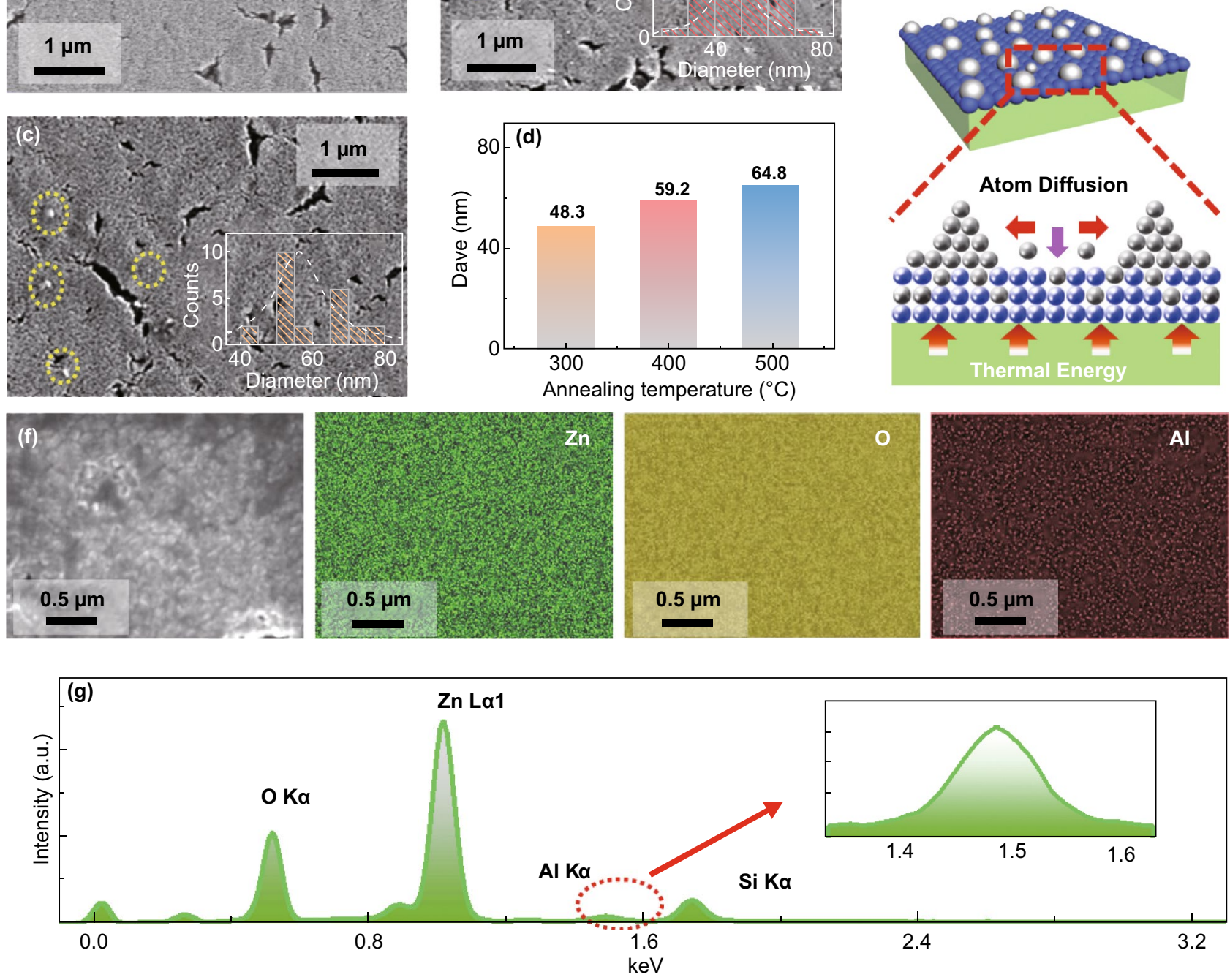

Fig. 2 SEM images of the a pristine $\mathrm{ZnO}, \mathrm{Al} / \mathrm{ZnO}$ heterostructures fabricated at $\mathbf{b} 300{ }^{\circ} \mathrm{C}$ and $\mathbf{c} 400{ }^{\circ} \mathrm{C}$. (Insets) The size distribution histograms of the resulting Al NSs. d Average diameters $\left(D_{\text {ave }}\right)$ of the Al NSs fabricated at various annealing temperatures. e Schematics of the fabrication of the Al NSs on ZnO QD thin films. f EDS maps of the heterostructures fabricated at $500{ }^{\circ} \mathrm{C}$. $\mathbf{g}$ Corresponding EDS spectra

dependence on the $I_{\mathrm{ph}}$ was compared for the $\mathrm{Al} / \mathrm{ZnO}$ heterostructure photodetector at an identical bias of $10 \mathrm{~V}$ as shown in Fig. S4. Compared with the pristine $\mathrm{ZnO}$ photodetector, one order higher $I_{\mathrm{ph}}$ was constantly witnessed with the device $\mathrm{Al} / \mathrm{ZnO}-500$ with a variation of the light intensity from 0.5 to $6.9 \mathrm{~mW} \mathrm{~cm}^{-2}$ as revealed in Fig. 3e. Consequently, the $R_{s}$ of the device $\mathrm{Al} / \mathrm{ZnO}-500$ significantly increased by 11 times to $\sim 528.5 \mathrm{~mA} \mathrm{~W}^{-1}$ when compared with the pristine $\mathrm{ZnO}$ device at $6.9 \mathrm{~mW} \mathrm{~cm}^{-2}$, and it further increased to $\sim 779.5 \mathrm{~mA} \mathrm{~W}^{-1}$ at $0.5 \mathrm{~mW} \mathrm{~cm}^{-2}$ as shown in 

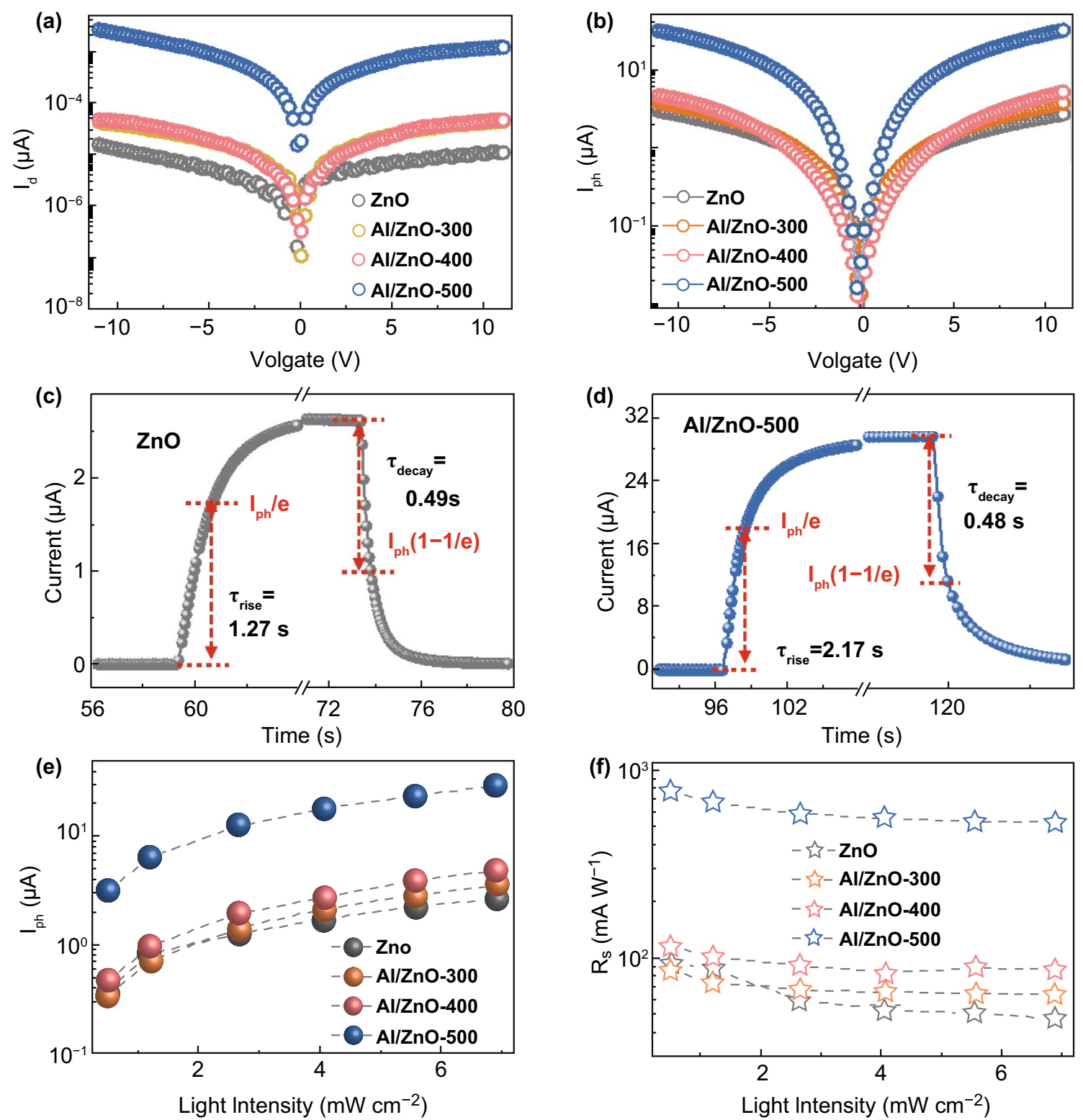

Fig. 3 Photoresponse of the $\mathrm{Al} / \mathrm{ZnO}$ heterostructure UV photodetectors fabricated at various temperatures. Current-voltage curves of each device $\mathbf{a}$ in the dark and $\mathbf{b}$ under $365 \mathrm{~nm}$ light illumination $\left(6.9 \mathrm{~mW} \mathrm{~cm}{ }^{-2}\right)$ at a $10 \mathrm{~V}$ bias. Time-resolved photoresponse of the $\mathbf{c}$ pristine $\mathrm{ZnO}$ and $\mathbf{d ~} \mathrm{Al} / \mathrm{ZnO}$ devices under $365 \mathrm{~nm}$ light illumination at a $10 \mathrm{~V}$ bias. e Photocurrent and $\mathbf{f}$ photoresponsivity of each device under $365 \mathrm{~nm} \mathrm{UV}$ illumination as a function of light intensities

Fig. 3f. Under the light intensity of $0.5 \mathrm{~mW} \mathrm{~cm}^{-2}$, the device $\mathrm{Al} / \mathrm{ZnO}-500$ also showed an excellent $\mathrm{EQE}$ of $\sim 264.8 \%$, which was about 8.3 times higher than that of the pristine $\mathrm{ZnO}$ detector as shown in Fig. S5a. As an aggregative indicator to evaluate the performance of a photodetector, the normalized detectivity $\left(D^{*}\right)$ can be expressed by Eq. 4 [12]:
$D^{*}=\frac{\left(I_{\mathrm{ph}}-I_{\mathrm{d}}\right)}{P_{0} \sqrt{2 q I_{\mathrm{d}} A}}$

where $q$ is the elementary charge. Although the distinct increases in $I_{\mathrm{ph}}$ were achieved by introducing the Al NSs, the $D^{*}$ of the $\mathrm{Al} / \mathrm{ZnO}$ heterostructure photodetectors slightly deteriorated due to the elevated $I_{\mathrm{d}}$ as shown in Fig. S5b. However, the $D^{*}$ of the device $\mathrm{Al} / \mathrm{ZnO}-300$ still maintained 
Table 1 The dark current $\left(I_{\mathrm{d}}\right)$, photocurrent $\left(I_{\mathrm{ph}}\right)$, photoresponsivity $\left(R_{s}\right)$, and the external quantum efficiency (EQE) of the pristine $\mathrm{ZnO}$ and heterostructure photodetectors; the applied bias voltage was $10 \mathrm{~V}$

\begin{tabular}{lcrcr}
\hline Samples & $I_{\mathrm{d}}(\mathrm{nA})$ & $I_{\mathrm{ph}}(\mu \mathrm{A})$ & $R_{s}\left(\mathrm{~mA} \mathrm{~W}^{-1}\right)$ & $\mathrm{EQE}(\%)$ \\
\hline $\mathrm{ZnO}$ & 0.039 & 2.63 & 47.64 & 16.19 \\
$\mathrm{ZnO} / \mathrm{Al}$ & 0.03 & 2.84 & 51.49 & 17.49 \\
$\mathrm{Al} / \mathrm{ZnO}-300$ & 0.11 & 3.54 & 64.13 & 21.79 \\
$\mathrm{Al} / \mathrm{ZnO}-400$ & 2.57 & 4.79 & 86.67 & 29.45 \\
$\mathrm{Al} / \mathrm{ZnO}-500$ & 26.1 & 29.20 & 528.51 & 179.55 \\
$\mathrm{Al} / \mathrm{ZnO}-8 \mathrm{~nm}$ & $1.49 \times 10^{5}$ & 768.29 & $11,220.91$ & 3812.03 \\
$\mathrm{Al} / \mathrm{ZnO}-10 \mathrm{~nm}$ & $4.04 \times 10^{5}$ & 1065.2 & $11,976.45$ & 4068.71 \\
\hline
\end{tabular}

comparable with that of the pristine $\mathrm{ZnO}$ one, and it was still superior to the performance of $\mathrm{ZnO}$ photodetectors in previous works [33, 34].

To ascertain the enhancement mechanism for the photodetectors, the light-mater interactions for the $\mathrm{Al} / \mathrm{ZnO}$ heterostructure photodetectors were investigated as shown in Fig. 4. As revealed shown in Fig. 4a, the absorption edge peaks appeared below $375 \mathrm{~nm}$ for each device, and the absorption peaks of the $\mathrm{Al} / \mathrm{ZnO}$ heterostructures slightly increased as a result of the intensive light confinement with LSPR. Given that, the inter-diffusion of $\mathrm{Al}$ atoms can result in a strong electronegative mismatch between $\mathrm{Zn}$ and $\mathrm{Al}$ atoms and emergence of impurity energy level in the bandgap of $\mathrm{ZnO}$ [35], a gradual redshift of optical bandgap from $3.36 \mathrm{eV}$ (the pristine $\mathrm{ZnO}$ ) to $3.325 \mathrm{eV}$ (the $\mathrm{Al} / \mathrm{ZnO}-500$ sample) was observed. As shown in Fig. 4b, the relationship between the light intensity and photocurrent for the pristine $\mathrm{ZnO}$ and $\mathrm{Al} / \mathrm{ZnO}-500$ devices was fitted by Eq. 5 [36]:

$I_{\mathrm{ph}} \propto P_{0}^{\theta}$

where $\theta$ is the power law factor. The value of $\theta$ increased from 0.72 (pristine $\mathrm{ZnO}$ ) to $0.88(\mathrm{Al} / \mathrm{ZnO}-500)$, suggesting the generation of additional electron-hole pairs with the existence of the $\mathrm{Al} \mathrm{NSs} \mathrm{[15].} \mathrm{Compared} \mathrm{to} \mathrm{pristine} \mathrm{ZnO}$, the NBE peaks at $\sim 372 \mathrm{~nm}$ and DLE peaks at $\sim 560 \mathrm{~nm}$ were drastically increased for the $\mathrm{Al} / \mathrm{ZnO}$ heterostructures as shown in Fig. 4c, which can be resulted from the intensified recombination of the excess carriers excited with the concentrated lights and the "hot electrons" injection from the Al NSs [37]. Whereas, the near-surface electromagnetic fields were gradually boosted by the Al NSs with a larger dimension at higher temperatures, inhibiting the recombination of the electron-hole pairs for the PL emission. Figure $4 d$ shows the deconvolution of the $\mathrm{Al} 2 \mathrm{p}_{3 / 2}$ XPS peak of $\mathrm{Al} /$ $\mathrm{ZnO}-500$ sample. The metallic Al peak at $\sim 72.2 \mathrm{eV}$ and oxidized $\mathrm{Al}$ peak at $\sim 74.2 \mathrm{eV}$ were simultaneously observed in the Gaussian fitted asymmetry peak, manifesting the coexistence of the $\mathrm{Al} \mathrm{NSs}$ and the inter-diffusion of $\mathrm{Al}$ atoms [38]. In addition, the band diagrams of the Al NSs and $\mathrm{ZnO}$ QD in the dark and under UV light illumination is depicted in Fig. 4e, f. Given that $\mathrm{ZnO}$ nanostructures possess a higher work function of 5.2-5.3 eV than that of $\mathrm{Al}(\sim 4.3 \mathrm{eV})$ [39], the downward band bending spontaneously formed as shown in Fig. 4e. As shown in Fig. 4f, the excited "hot electrons" from the Al NSs with the UV lights partially injected into the conductive band of $\mathrm{ZnO}$, which further resulted in the increases of the $I_{\mathrm{ph}}$.

\subsection{Deposition Thickness Effect on Device Performance}

The morphological evolution of the self-assembled Al NSs on the $\mathrm{ZnO}$ QD thin films was investigated over a control of deposition thicknesses between 6 and $10 \mathrm{~nm}$, and the performance of the $\mathrm{Al} / \mathrm{ZnO}$ heterostructure photodetectors is shown in Fig. 5. After annealing at an identical temperature of $50{ }^{\circ} \mathrm{C}$, the shape development of the $\mathrm{Al} \mathrm{NSs} \mathrm{from} \mathrm{tiny} \mathrm{semi-}$ sphere to almond-shape was witnessed with the increased deposition thicknesses as shown in Figs. 5a and S6. By providing with additional $\mathrm{Al}$ atoms, $\mathrm{Al} \mathrm{NSs}$ tended to absorb surrounded atoms to reduce the total surface energy, and thus the size of the Al NSs radically increased at the expense of the density. As a result, at $8 \mathrm{~nm}$, the average dimension of long axis $(D 1)$ and minor axis $(D 2)$ for the resulting Al NSs were $\sim 78.1$ and $\sim 45.4 \mathrm{~nm}$, respectively, accompanied with the average density of $\sim 3.2 \times 10^{7}$ (shown in Table S1). With the deposition thickness increased to $10 \mathrm{~nm}$, the $D 1$ and $D 2$ correspondingly increased to $\sim 95.6$ and $\sim 46.3 \mathrm{~nm}$, and the density slightly decreased to $\sim 2.5 \times 10^{7}$. Meanwhile, excess $\mathrm{Al}$ atoms participated the inter-diffusion with the increased deposition thicknesses, leading to the increased $I_{\mathrm{d}}$ due to the improved conductivity as shown in Fig. S7. Compared with the device $\mathrm{Al} / \mathrm{ZnO}-6 \mathrm{~nm}$, the obvious enhancement in the $I_{\mathrm{ph}}$ was evidenced as a function of deposition thicknesses, and the $I_{\mathrm{ph}}$ of the device Al/ZnO- $10 \mathrm{~nm}$ drastically increased by 36.5 times to $\sim 1065.2 \mu \mathrm{A}$ at a bias of $10 \mathrm{~V}$ as revealed in Fig. $5 \mathrm{~b}$ and Table 1. Correspondingly, the $R_{s}$ and EQE of the device $\mathrm{Al} / \mathrm{ZnO}-10 \mathrm{~nm}$ increased to $11.98 \mathrm{~A} \mathrm{~W}^{-1}$ and 

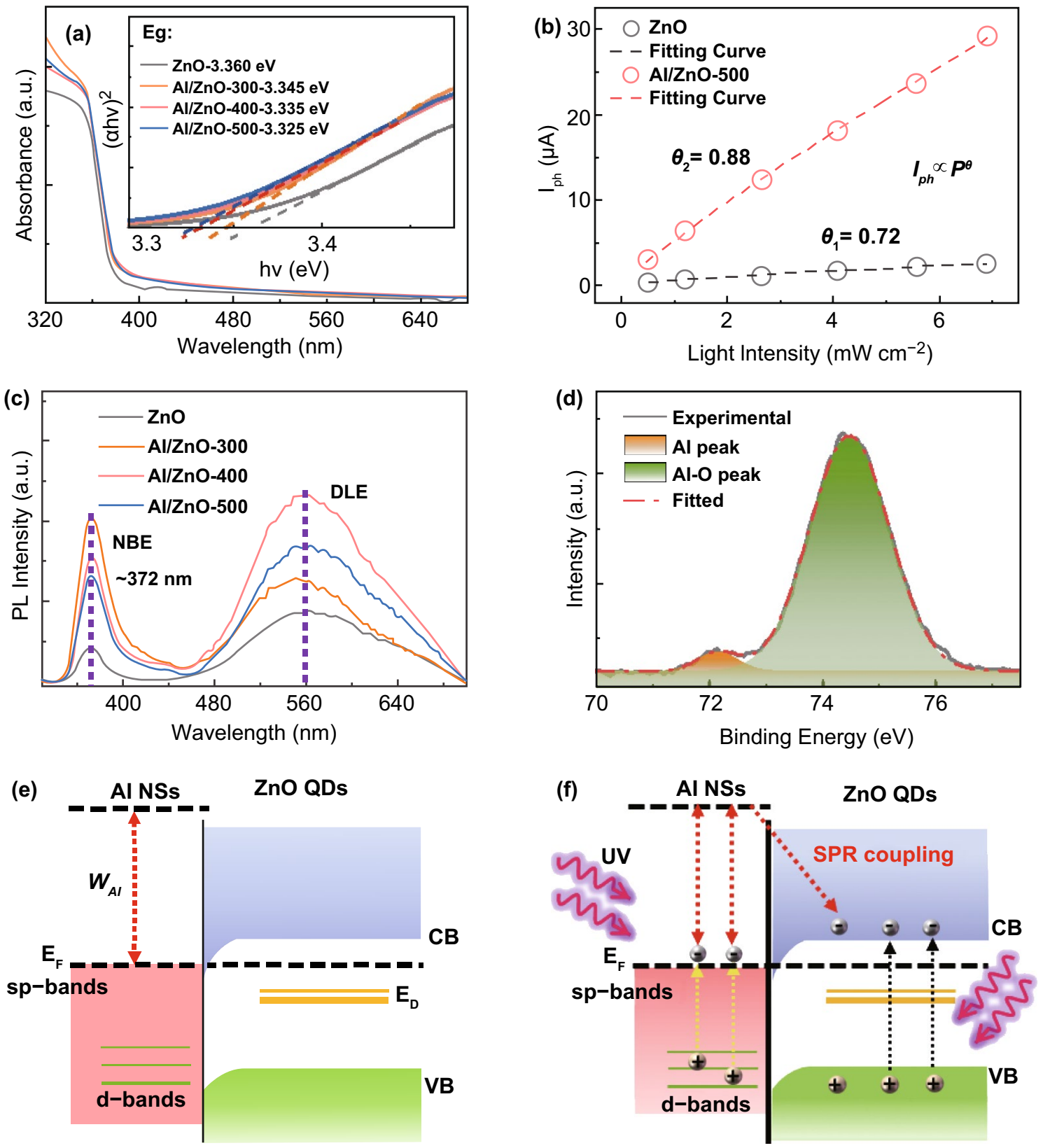

Fig. 4 a Absorbance spectra of the $\mathrm{Al} / \mathrm{ZnO}$ heterostructures fabricated at different temperatures. (Inset) Tauc plots of the heterostructures. b The light intensity dependence on photocurrent for the pristine $\mathrm{ZnO}$ and $\mathrm{Al} / \mathrm{ZnO}$ photodetectors. c Room-temperature PL emission spectra of the photodetectors. $\mathbf{d}$ XPS spectra of $\mathrm{Al} 2 \mathrm{p} 3 / 2$ signatures on the $\mathrm{Al} / \mathrm{ZnO}-500$. The band diagrams of $\mathrm{Al} / \mathrm{ZnO}$ photodetectors $\mathbf{e}$ in the dark and $\mathbf{f}$ under UV light illumination

4068.7\% as shown in Fig. 5c, which were apparently superior to the $\mathrm{ZnO}$ photodetector in previous works as summarized in Table 2. Regardless of the deposition thicknesses, each photodetector exhibited a fast response as evidenced in Fig. S8. In addition, the carrier mobility for $\mathrm{Al} / \mathrm{ZnO}$ heterostructure slightly increased compared to the pristine $\mathrm{ZnO}$, as shown in Fig. S9, which partially was of benefit for the improvement of photocurrent. To comprehensively evaluate the performance parameters, the device $\mathrm{Al} / \mathrm{ZnO}-500$ could be an 

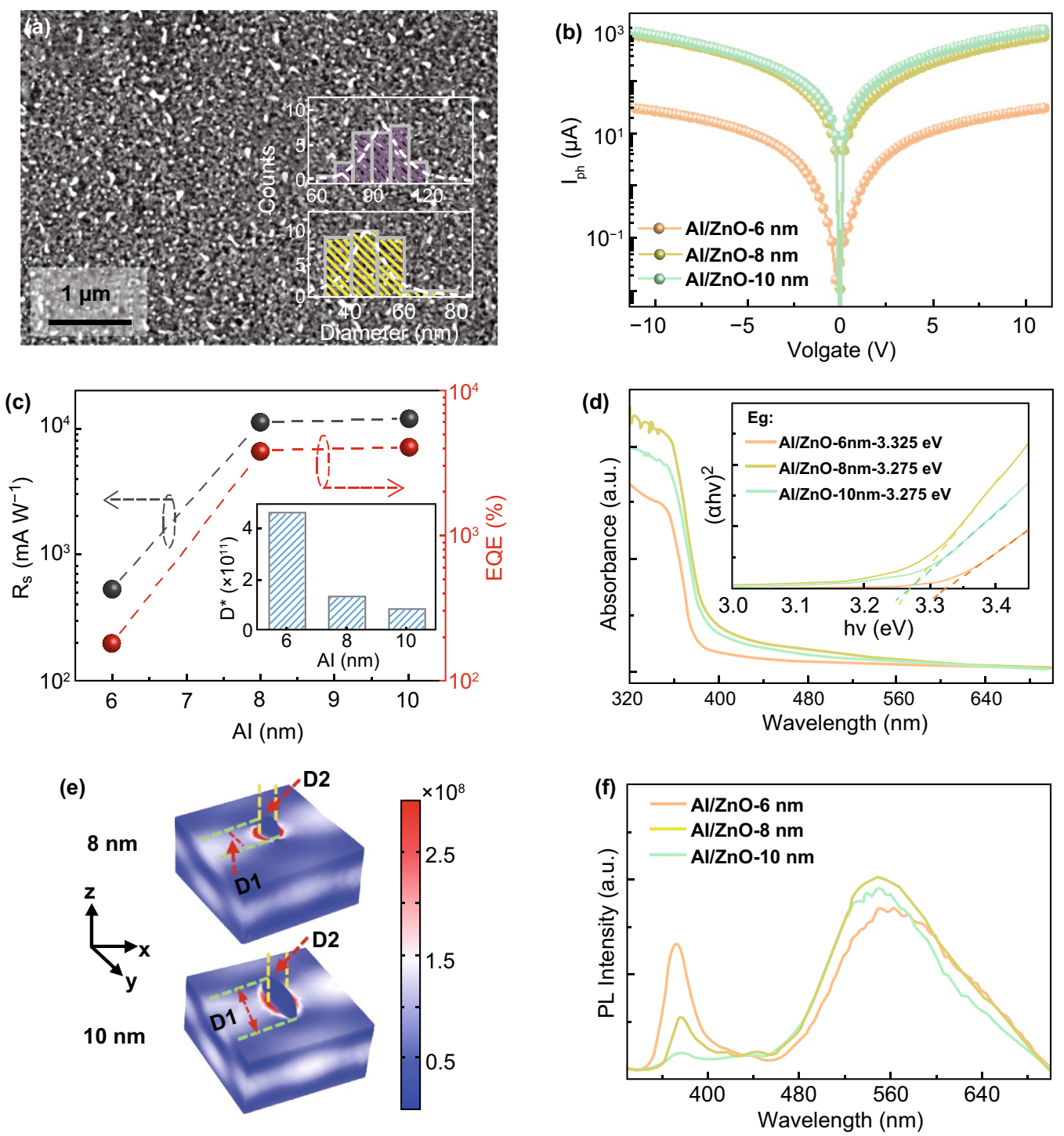

Fig. 5 Photoresponse of the $\mathrm{Al} / \mathrm{ZnO}$ heterostructure photodetectors fabricated with a variation of deposition thicknesses. a SEM image of the device $\mathrm{Al} / \mathrm{ZnO}-10 \mathrm{~nm}$. b Current-voltage curves of the devices under $365 \mathrm{~nm}$ light illumination $\left(6.9 \mathrm{~mW} \mathrm{~cm}^{-2}\right)$. c Photoresponsivity (gray) and EQE (red) of the phtodetectors fabricated with various $\mathrm{Al}$ deposition thicknesses. (Insets) The normalized detectivity $\left(D^{*}\right)$ of each device. d Absorbance spectra of the $\mathrm{Al} / \mathrm{ZnO}$ heterostructures. (Inset) The corresponding Tauc plots. e The EM filed distribution of the samples Al/ $\mathrm{ZnO}-8 \mathrm{~nm}$ and $\mathrm{Al} / \mathrm{ZnO}-10 \mathrm{~nm}$. f Room-temperature PL emission spectra of the samples

optimal photodetector with relatively high responsivity and fast response speed.

The absorbance spectra of the devices fabricated with various $\mathrm{Al}$ deposition thicknesses are shown in Fig. $5 \mathrm{~d}$. With the increased deposition thicknesses, the absorption below $\sim 375 \mathrm{~nm}$ gradually elevated due to the enhanced LSPR, and the optical bandgap slightly decreased from $\sim 3.325$ to $\sim 3.275 \mathrm{eV}$ because of the intensified interdiffusion of $\mathrm{Al}$ atoms. As shown in Fig. 5e, the size expansion of the Al NSs directly resulted in much more drastic EM fields distributed in ZnO layers, and the NBE peak correspondingly decreased due to the inhibited recombination of electron-hole as shown in Fig. 5f. 
Table 2 Performance comparison of the $\mathrm{ZnO}$ UV photodetectors with various configurations and materials

\begin{tabular}{|c|c|c|c|c|c|c|c|}
\hline Materials & Light source & $\operatorname{Bias}(\mathrm{V})$ & $I_{\mathrm{ph}}(\mu \mathrm{A})$ & $R_{s}\left(\mathrm{~mA} \mathrm{~W}^{-1}\right)$ & $t_{\text {rise }}(\mathrm{s})$ & $t_{\text {decay }}(\mathrm{s})$ & EQE $(\%)$ \\
\hline $\mathrm{P}-\mathrm{ZnO}-\mathrm{Au}[40]$ & $245 \mathrm{~nm}$ & 5 & $\sim 10$ & - & 24 & 15 & - \\
\hline 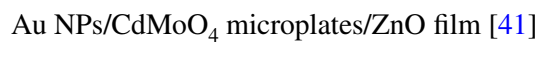 & $\begin{array}{l}350 \mathrm{~nm}, 450 \mathrm{~W} \text { Xe lamp } \\
\text { with a monochromator }\end{array}$ & 5 & 0.289 & 321.1 & 16 & 9.2 & - \\
\hline Au NPs/ZnO nanowires [42] & $350 \mathrm{~nm} 1.3 \mathrm{~mW} \mathrm{~cm}{ }^{-2}$ & 1 & $\sim 0.65$ & - & 25 & 10 & - \\
\hline Au NPs/p-ZnO NSs/n-ZnO [43] & $365 \mathrm{~nm}, 6.0 \mathrm{~mW} \mathrm{~cm}{ }^{-2}$ & 1 & - & 25.4 & $\sim 70$ & $\sim 150$ & 8.7 \\
\hline Ag NWs/ZnO branched nanorods [44] & $365 \mathrm{~nm}, 5 \mathrm{~mW} \mathrm{~cm}{ }^{-2}$ & 5 & 250 & 2500 & - & 1 & - \\
\hline $\mathrm{ZnO}$ nanotetrapod network [45] & $360 \mathrm{~nm}, 15 \mathrm{~W} \mathrm{~cm}^{-2}$ & 2.4 & - & - & 0.067 & 0.03 & - \\
\hline $\mathrm{BiOCl} / \mathrm{ZnO}[10]$ & $350 \mathrm{~nm}, 150 \mu \mathrm{W} \mathrm{cm}-2$ & 5 & $\sim 0.1$ & 182.2 & 29.23 & 11.2 & - \\
\hline Graphene nanodot/ZnO [5] & $300 \mathrm{~nm}, 403 \mu \mathrm{W} \mathrm{cm}{ }^{-2}$ & 5 & 0.043 & 22.5 & - & - & 9.32 \\
\hline $\mathrm{Al} / \mathrm{ZnO}-500$ (this work) & $365 \mathrm{~nm}, 500 \mu \mathrm{W} \mathrm{cm}-2$ & 10 & 3.14 & 779.5 & 2.17 & 0.48 & 264.8 \\
\hline $\mathrm{Al} / \mathrm{ZnO}-10 \mathrm{~nm}$ (this work) & $365 \mathrm{~nm}, 6.9 \mathrm{~mW} \mathrm{~cm}{ }^{-2}$ & 10 & 1065.2 & $11,976.45$ & 6.9 & 19.4 & 4068.71 \\
\hline
\end{tabular}

\section{Conclusion}

In conclusion, we proposed novel $\mathrm{Al} / \mathrm{ZnO}$ heterostructures for the fabrication of high-performance UV photodetectors with a comprehensive investigation of the topological effects on the photoresponse of the devices. With a variation of the annealing temperatures, the average diameter of the self-assembled Al NSs gradually evolved from $\sim 48.3$ to $\sim 64.8 \mathrm{~nm}$ due to the accelerated aggregation with a broadened diffusion length of $\mathrm{Al}$ atoms. Depending on the deposition thicknesses, the morphological evolution of the $\mathrm{Al}$ NSs from the semi-spherical shape to almond shape was observed even at an identical annealing temperature. The optical properties of the $\mathrm{Al} / \mathrm{ZnO}$ heterostructures sensitively developed along with the morphological evolution of the resulting Al NSs resulting from the variation of the EM fields. The photoresponse of the devices was also determined by the configuration of the heterostructures, resulting in a superior photocurrent of $1.065 \mathrm{~mA}$ with a photoresponsivity of $11.98 \mathrm{~A} \mathrm{~W}^{-1}$ under $6.9 \mathrm{~mW} \mathrm{~cm}^{-2} \mathrm{UV}$ light illumination at a bias of $10 \mathrm{~V}$. The relatively lower photoresponse time of $\sim 0.79 \mathrm{~s} / \sim 0.24 \mathrm{~s}\left(\tau_{\text {rise }} / \tau_{\text {decay }}\right)$ than that of the pristine $\mathrm{ZnO}$ device was obtained for the $\mathrm{Al} / \mathrm{ZnO}$ heterostructure photodetectors, suggesting a fast response speed of the devices.

Acknowledgements The authors acknowledge the National Natural Science Foundation of China (Grant Nos. 61705070 and 61974052), China Postdoctoral Science Foundation (Grant Nos. 2019M662594), National Research Foundation of Korea (NRF) Grant funded by the Korean Government (MSIP) (Nos. NRF2019R1A2C4069438 and NRF-2018R1A6A1A03025242).
Open Access This article is licensed under a Creative Commons Attribution 4.0 International License, which permits use, sharing, adaptation, distribution and reproduction in any medium or format, as long as you give appropriate credit to the original author(s) and the source, provide a link to the Creative Commons licence, and indicate if changes were made. The images or other third party material in this article are included in the article's Creative Commons licence, unless indicated otherwise in a credit line to the material. If material is not included in the article's Creative Commons licence and your intended use is not permitted by statutory regulation or exceeds the permitted use, you will need to obtain permission directly from the copyright holder. To view a copy of this licence, visit http://creativecommons.org/licenses/by/4.0/.

Electronic supplementary material The online version of this article (https://doi.org/10.1007/s40820-020-00455-9) contains supplementary material, which is available to authorized users.

\section{References}

1. M.-Y. Li, M. Yu, D. Su, J. Zhang, S. Jiang, J. Wu, Q. Wang, S. Liu, Ultrahigh responsivity UV photodetector based on $\mathrm{Cu}$ nanostructure/ZnO QD hybrid architectures. Small 15, 1901606 (2019). https://doi.org/10.1002/smll.201901606

2. S. Mitra, A. Aravindh, G. Das, Y. Pak, I. Ajia, K. Loganathan, E. Di Fabrizio, I.S. Roqan, High-performance solarblind flexible deep-UV photodetectors based on quantum dots synthesized by femtosecond-laser ablation. Nano Energy 48, 551-559 (2018). https://doi.org/10.1016/j.nanoen.2018.03.077

3. C. Xie, X.T. Lu, X.W. Tong, Z.X. Zhang, F.X. Liang, L. Liang, L.B. Luo, Y.C. Wu, Ultrawide-bandgap semiconductors: recent progress in solar-blind deep-ultraviolet photodetectors based on inorganic ultrawide bandgap semiconductors. Adv. Funct. Mater. 29, 1806006 (2019). https://doi.org/10.1002/ adfm.201970057 
4. N. Nasiri, R. Bo, F. Wang, L. Fu, A. Tricoli, Ultraporous electron-depleted $\mathrm{ZnO}$ nanoparticle networks for highly sensitive portable visible-blind UV photodetectors. Adv. Mater. 27, 4336-4343 (2015). https://doi.org/10.1002/adma.20150 1517

5. R. Tang, S. Han, F. Teng, K. Hu, Z. Zhang, M. Hu, X. Fang, Size-controlled graphene nanodot arrays/ZnO hybrids for high-performance UV photodetectors. Adv. Sci. 5, 1700334 (2018). https://doi.org/10.1002/advs.201700334

6. G. Li, M. Suja, M. Chen, E. Bekyarova, R.C. Haddon, J. Liu, M.E. Itkis, Visible-blind UV photodetector based on single-walled carbon nanotube thin film/ZnO vertical heterostructures. ACS Appl. Mater. Interfaces 9(42), 37094-37104 (2017). https://doi.org/10.1021/acsami.7b07765

7. B. Zhao, F. Wang, H. Chen, L. Zheng, L. Su, D. Zhao, X. Fang, An ultrahigh responsivity $\left(9.7 \mathrm{~mA} \mathrm{~W}^{-1}\right)$ self-powered solar-blind photodetector based on individual $\mathrm{ZnO}-\mathrm{Ga}_{2} \mathrm{O}_{3}$ heterostructures. Adv. Funct. Mater. 27, 1700264 (2017). https://doi.org/10.1002/adfm.201700264

8. L. Li, L. Gu, Z. Lou, Z. Fan, G. Shen, ZnO quantum dot decorated $\mathrm{Zn}_{2} \mathrm{SnO}_{4}$ nanowire heterojunction photodetectors with drastic performance enhancement and flexible ultraviolet image sensors. ACS Nano 11(4), 4067-4076 (2017). https://doi.org/10.1021/acsnano.7b00749

9. B. Ouyang, K. Zhang, Y. Yang, Self-powered UV photodetector array based on $\mathrm{P}_{3} \mathrm{HT} / \mathrm{ZnO}$ nanowire array heterojunction. Adv. Mater. Technol. 2, 1700208 (2017). https://doi. org/10.1002/admt.201700208

10. F. Teng, W. Ouyang, Y. Li, L. Zheng, X. Fang, Novel structure for high performance UV photodetector based on BiOCl/ZnO hybrid film. Small 13, 1700156 (2017). https:// doi.org/10.1002/smll.201700156

11. L. Hu, J. Yan, M. Liao, H. Xiang, X. Gong, L. Zhang, X. Fang, An optimized ultraviolet light photodetector with wide-range photoresponse based on $\mathrm{ZnS} / \mathrm{ZnO}$ biaxial nanobelt. Adv. Mater. 24, 2305-2309 (2012). https://doi. org/10.1002/adma.201200512

12. D. You, C. Xu, W. Zhang, J. Zhao, F. Qin, Z. Shi, Photovoltaic-pyroelectric effect coupled broadband photodetector in self-powered $\mathrm{ZnO} / \mathrm{ZnTe}$ core/shell nanorod arrays. Nano Energy 62, 310-318 (2019). https://doi.org/10.1016/j.nanoe n.2019.05.050

13. F. Cao, W. Tian, B. Gu, Y. Ma, H. Lu, L. Li, High-performance UV-vis photodetectors based on electrospun $\mathrm{ZnO}$ nanofiber-solution processed perovskite hybrid structures. Nano Res. 10(7), 2244-2256 (2017). https://doi. org/10.1007/s12274-016-1413-2

14. Y. Jin, J. Wang, B. Sun, J.C. Blakesley, N.C. Greenham, Solution-processed ultraviolet photodetectors based on colloidal ZnO nanoparticles. Nano Lett. 8(6), 1649-1653 (2008). https://doi.org/10.1021/n10803702

15. J. Lu, C. Xu, J. Dai, J. Li, Y. Wang, Y. Lin, P. Li, Improved UV photoresponse of $\mathrm{ZnO}$ nanorod arrays by resonant coupling with surface plasmons of Al nanoparticles. Nanoscale 7, 3396-3403 (2015). https://doi.org/10.1039/C4NR07114J
16. H. Chen, L. Su, M. Jiang, X. Fang, Highly desirable photodetectors derived from versatile plasmonic nanostructures. Adv. Funct. Mater. 27, 1704181 (2017). https://doi. org/10.1002/adfm.201704181

17. S. Chen, Y. Wang, Q. Liu, G. Shi, Z. Liu et al., Broadband enhancement of $\mathrm{PbS}$ quantum dot solar cells by the synergistic effect of plasmonic gold nanobipyramids and nanospheres. Adv. Energy Mater. 8, 1701194 (2018). https://doi. org/10.1002/aenm.201701194

18. J. Lu, J. Li, C. Xu, Y. Li, J. Dai, Y. Wang, Y. Lin, S. Wang, Direct resonant coupling of Al surface plasmon for ultraviolet photoluminescence enhancement of $\mathrm{ZnO}$ microrods. ACS Appl. Mater. Interfaces 6(20), 18301-18305 (2014). https:// doi.org/10.1021/am505492r

19. P.R. West, S. Ishii, G.V. Naik, N.K. Emani, V.M. Shalaev, A. Boltasseva, Searching for better plasmonic materials. Laser Photonics Rev. 4, 795-808 (2010). https://doi.org/10.1002/ lpor.200900055

20. M. Chen, X. Wang, Y.H. Yu, Z.L. Pei, X.D. Bai, C. Sun, R.F. Huang, L.S. Wen, X-ray photoelectron spectroscopy and auger electron spectroscopy studies of Al-doped $\mathrm{ZnO}$ films. Appl. Surf. Sci. 158(1), 134-140 (2000). https://doi. org/10.1016/S0169-4332(99)00601-7

21. S. Liu, M.-Y. Li, D. Su, M. Yu, H. Kan, H. Liu, X. Wang, S. Jiang, Broad-band high-sensitivity $\mathrm{ZnO}$ colloidal quantum dots/self-assembled Au nanoantennas heterostructures photodetectors. ACS Appl. Mater. Interfaces 10(38), 3251632525 (2018). https://doi.org/10.1021/acsami.8b09442

22. D. Su, S. Jiang, M. Yu, G. Zhang, H. Liu, M.-Y. Li, Facile fabrication of configuration controllable self-assembled Al nanostructures as UV SERS substrates. Nanoscale 10, 22737-22744 (2018). https://doi.org/10.1039/C8NR08555B

23. J.R. Lakowicz, Radiative decay engineering metal-enhanced fluorescence and plasmon emission. Anal. Biochem. 337, 171-194 (2005). https://doi.org/10.1039/C8NR08555B

24. K. Mohmood, S.B. Park, Atmospheric pressure based electrostatic spray deposition of transparent conductive $\mathrm{ZnO}$ and Al-doped $\mathrm{ZnO}$ (AZO) thin films: effects of Al doping and annealinng treatment. Electron. Mater. Lett. 9, 161-170 (2013). https://doi.org/10.1007/s 13391-012-2188-6

25. P. Wang, Y. Wang, L. Ye, M. Wu, R. Xie et al., Ferroelectric localized field-enhanced $\mathrm{ZnO}$ nanosheet ultraviolet photodetector with high sensitivity and low dark current. Small 14, 1800492 (2018). https://doi.org/10.1002/smll.201800492

26. Y. Wang, R. Fullon, M. Acerce, C.E. Petoukhoff, J. Yang et al., Solution-processed $\mathrm{MoS}_{2}$ /organolead trihalide perovskite photodetectors. Adv. Mater. 29, 1603995 (2017). https://doi. org/10.1002/adma.201603995

27. M.-Y. Li, M. Sui, P. Pandey, Q. Zhang, E.-S. Kim, J. Lee, Systematic control of self-assembled Au nanoparticles and nanostructures through the variation of deposition amount, annealing duration, and temperature on Si (111). Nanoscale Res. Lett. 10, 380 (2015). https://doi.org/10.1186/s 1167 $1-015-1084-\mathrm{Z}$ 
28. M.-Y. Li, Q. Zhang, P. Pandey, M. Sui, E.-S. Kim, J. Lee, From the Au nano-clusters to the nanoparticles on $4 \mathrm{H}-\mathrm{SiC}(0001)$. Sci. Rep. 5, 13954 (2015). https://doi.org/10.1038/srep13954

29. J. Lu, C. Xu, J. Dai, J. Li, Y. Wang, Y. Lin, P. Li, Plasmonenhanced whispering gallery mode lasing from hexagonal $\mathrm{Al} /$ ZnO microcavity. ACS Photonics 2(1), 73-77 (2015). https:// doi.org/10.1021/ph5002582

30. L. Meng, G. Li, X. Tian, S. Bao, Q. Xu et al., Ultrasensitive fiber-based $\mathrm{ZnO}$ nanowire neteork ultraviolet photodetector enabled by the synergism between interface and surface gating effects. ACS Appl. Mater. Interfaces (2020). https://doi. org/10.1021/acsami.9b18185

31. X. Liu, L. Gu, Q. Zhang, J. Wu, Y. Long, Z. Fan, All-printable band-edge modulated $\mathrm{ZnO}$ nanowire photodetectors with ultra-high detectivity. Nat. Commun. 5, 4007 (2014). https:// doi.org/10.1038/ncomms5007

32. Z. Jin, Q. Zhou, Y. Chen, P. Mao, H. Li, H. Liu, J. Wang, Y. $\mathrm{Li}$, Graphdiyne: $\mathrm{ZnO}$ nanocomposites for high-performance UV photodetectors. Adv. Mater. 28, 3697 (2016). https://doi. org/10.1002/adma.201600354

33. J. Yu, N. Tian, High spectrum selectivity and enhanced responsivity of a $\mathrm{ZnO}$ ultraviolet photodetector realized by the addition of $\mathrm{ZnO}$ nanoparticles layer. Phys. Chem. Chem. Phys. 18, 24129-24133 (2016). https://doi.org/10.1039/C6CP03504C

34. L. Li, Y. Zhang, R. Wang, J. Sun, Y. Si, H. Wang, C. Pan, Y. Dai, Ferroelectricity-induced performance enhancement of $\mathrm{V}$-doped $\mathrm{ZnO} / \mathrm{Si}$ photodetector by direct energy band modlation. Nano Energy 65, 104046 (2019). https://doi. org/10.1016/j.nanoen.2019.104046

35. M. Ahmad, E. Ahmed, Y. Zhang, N.R.K. Xu, M. Ullah, Z. Hong, F.K. Shan, Y.S. Yu, Preparation of highly efficient Al-doped $\mathrm{ZnO}$ photocatalyst by combustion synthesis. Curr. Appl. Phys. 13, 697-704 (2013). https://doi.org/10.1016/j. cap.2012.11.008

36. K. Shen, X. Li, H. Xu, M. Wang, X. Dai et al., Enhanced performance of $\mathrm{ZnO}$ nanoparticle decorated all-inorganic $\mathrm{CsPbBr} 3$ quantum dot photodetectors. J. Mater. Chem. A 7, 6134-6142 (2019). https://doi.org/10.1039/C9TA00230H

37. T. Dixit, I.A. Palani, V. Singh, Role of surface plasmon decay mediated hot carriers toward the photoluminescence tuning of metal-coated ZnO nanorods. J. Phys. Chem. C 121, 35403548 (2017). https://doi.org/10.1021/acs.jpcc.6b11526

38. H.T. Cao, Z.L. Pei, J. Gong, C. Sun, R.F. Huang, L.S. Wen, Preparation and characterization of $\mathrm{Al}$ and $\mathrm{Mn}$ doped $\mathrm{ZnO}$ (ZnO: (Al, Mn)) transparent conducting oxide films. J. Solid State Chem. 177, 1480-1487 (2004). https://doi.org/10.1016/j. jssc.2003.11.030

39. X. Wang, C.J. Summers, Z.L. Wang, Self-attraction among aligned $\mathrm{Au} / \mathrm{ZnO}$ nanorods under electron beam. Appl. Phys. Lett. 86, 013111 (2005). https://doi.org/10.1063/1.1847713

40. M. Sun, Z. Xu, M. Yin, Q. Lin, L. Lu et al., Broad-band three dimensional nanocave $\mathrm{ZnO}$ thin film photodetectors enhanced by Au surface plasmon resonance. Nanoscale 8, 8924-8930 (2016). https://doi.org/10.1039/C6NR00089D

41. W. Ouyang, F. Teng, M. Jiang, X. Fang, ZnO film UV photodetector with enhanced performance: heterojunction with $\mathrm{CdMoO}_{4}$ microplates and the hot electron injection effect of Au nanoparticles. Small 13, 1702177 (2017). https://doi. org/10.1002/smll.201702177

42. K. Liu, M. Sakurai, M. Liao, M. Aono, Giant improvement of the performance of $\mathrm{ZnO}$ nanowire photodetectors by $\mathrm{Au}$ nano-particles. J. Phys. Chem. C 114, 19835-19839 (2010). https://doi.org/10.1021/jp108320j

43. C.L. Hsu, Y.H. Lin, L.K. Wang, T.J. Hsueh, S.P. Chang, S.J. Chang, Tunable UV- and visible-light photoresponse based on $\mathrm{p}-\mathrm{ZnO}$ nanostructures/n- $\mathrm{ZnO} /$ glass peppered with $\mathrm{Au}$ nano-particles. ACS Appl. Mater. Interfaces 9, 14935-14944 (2017). https://doi.org/10.1021/acsami.7b03216

44. Z. Yang, M. Wang, Q. Zhao, H. Qiu, J. Li, X. Li, J. Shao, Dielectrophoretic-assembled single and parallel-aligned Ag nanowire-ZnO-branched nanorod heteronanowire ultraviolet photodetectors. ACS Appl. Mater. Interfaces 9, 22837 (2017). https://doi.org/10.1021/acsami.7b05485

45. D. Gedamu, I. Paulowicz, S. Kaps, O. Lupan, S. Wille, G. Haidarschi, Y.K. Mishra, R. Adelung, Rapid fabrication technique for interpenetrated $\mathrm{ZnO}$ nanotetrapod networks for fast UV sensors. Adv. Mater. 26, 1541 (2014). https://doi. org/10.1002/adma.201304363 